\title{
Prediksi Dampak Lingkungan Pengelolaan Sampah di TPA Jabon, Kabupaten Sidoarjo
}

\author{
Martha Lumban Gaol dan I D A A Warmadewanthi \\ Departemen Teknik Lingkungan, Fakultas Teknik Sipil dan Perencanaan, Institut Teknologi Sepuluh Nopember \\ (ITS) \\ Jl. Arief Rahman Hakim, Surabaya 60111 Indonesia \\ e-mail:warma@its.ac.id
}

\begin{abstract}
Abstrak-Tingginya jumlah penduduk Kabupaten Sidoarjo berbanding lurus dengan jumlah timbulan sampah yang dihasilkan individu maupun fasilitas umum. Namun, pelayanan pengelolaan sampah hanya sebesar 35\% dari total keseluruhan. Tempat Pemrosesan Akhir (TPA) Jabon merupakan satu-satunya TPA yang aktif di Kabupaten Sidoarjo dengan sistem controlled landfill sebagai metode panimbunan sampahnya. Lahan landfill akan diperkirakan penuh akhir tahun 2017 sehingga TPA Jabon sedang dalam proses peluasan lahan. Tujuan penelitian ini adalah menentukan skenario pengelolaan sampah di TPA yang menghasilkan dampak lingkungan paling kecil terhadap lingkungan. Metode analisis menggunakan Life Cycle Assessment (LCA) dengan menggunakan software SimaPro v.8.3 dan menggunakan metode Environmental Product Declaration (EPD). Jumlah timbulan sampah yang masuk ke TPA dihitung dengan metode load count analysis, karakteristik fisik dengan analisis proximat, analisis kimia sampah dengan analisis ultimat serta data penduduk Kabupaten Sidoarjo digunakan untuk proyeksi penduduk tahun 2027. Penelitian ini menggunakan 4 skenario pengelolaan sampah di TPA yakni skenario 0 (controlled landfill), skenario 1 (daur ulang, pengomposan, dan insinerasi), skenario 2 (daur ulang, pengomposan, dan sanitary landfill) dan skenario 3 (daur ulang, pengomposan, insinerasi, dan sanitary landfill). Hasil analisis dampak lingkungan menunjukkan bahwa skenario 2 merupakan skenario pengelolaan sampah yang tepat untuk TPA Jabon.
\end{abstract}

Kata Kunci-Life Cycle Assessment (LCA), skenario, pengelolaan sampah, Sidoarjo, TPA.

\section{PENDAHULUAN}

$\mathrm{K}$ ABUPATEN Sidoarjo merupakan kawasan urban (perkotaan), yang merupakan kawasan industri dan padat penduduk [1]. Hal ini mengakibatkan tingginya jumlah timbulan sampah yang dihasilkan baik individu maupun fasilitas umum. Kondisi ini berbanding terbalik dengan tingkat pelayanan pengelolaan sampah, yakni sebesar 38\% dari total keseluruhan sampah yang dihasilkan. Timbulan sampah yang dihasilkan tersebut diangkut dan diproses di Tempat Pemrosesan Akhir (TPA) sampah Jabon, yakni satu-satunya TPA yang masih aktif di Kabupaten Sidoarjo.

Jumlah timbulan sampah yang masuk ke TPA Jabon adalah sebesar 1206,65 m3/hari [2]. Pengelolaan sampah di TPA Jabon dilakukan dengan metode controlled landfill. Timbunan sampah di TPA tersebut dapat menghasilkan jejak karbon berupa biogas yang terdiri atas gas metan $\left(\mathrm{CH}_{4}\right)$ dan gas karbon dioksida $\left(\mathrm{CO}_{2}\right)$ yang mana kedua gas tersebut merupakan emisi Gas Rumah Kaca (GRK) yang berdampak terhadap pemanasan global [3]. Belum ada pengelolaan lingkungan berupa pengolahan lindi maupun pengolahan gas metan di TPA Jabon sehingga dampak negatif terhadap lingkungan akibat aktivitas TPA meningkat.

Menyikapi hal tersebut, Pemerintah Kabupaten Sidoarjo sedang dalam proses melakukan perluasan lahan TPA Jabon. Hal ini dikarenakan area timbunan sampah diperkirakan akan penuh pada akhir tahun 2017 sehingga diperlukan lahan tambahan untuk keberlangsungan pengelolaan sampah di TPA Jabon. Perluasan lahan tersebut harus didukung oleh skenario pengelolaan sampah di TPA sehingga sampah yang besar jumlahnya tersebut dapat dikelola dengan baik sehingga usia TPA menjadi lebih panjang dan dapat mengurangi dampak lingkungan yang dihasilkan. Manajemen persampahan adalah aspek lingkungan yang paling penting dalam hal perlindungan lingkungan dan harus menjadi prioritas utama [4].

Manajemen persampahan adalah permasalahan lingkungan yang harus dipertimbangkan secara baik, yakni dari segi aspek teknis, ekonomi terutama lingkungan [5]. Oleh karena itu, perlu dilakukannya penelitian terhadap Life Cycle Assessment (LCA) terhadap pengelolaan sampah di TPA Jabon, sehingga alternatif pengelolaan sampah di TPA sesuai dan mampu menjawab permasalahan lingkungan. Life Cycle Assessment (LCA) secara umum adalah metode untuk menganalisis beban lingkungan di semua tahapan dalam siklus hidup dari produk dimulai dari ekstraksi sumber daya, melalui proses produksi bahan, bagian produk, dan produk itu sendiri, serta penggunaan produk sampai produk itu dibuang (baik penggunaan kembali, daur ulang, atau pembuangan akhir), dengan kata lain cradle to grave [6].

Penelitian ini menganalisis 4 skenario pengelolaan sampah yakni skenario 0 (controlled landfill) sebagai skenario kondisi eksisting, dan skenario rencana yakni skenario 1 (daur ulang, pengomposan dan insinerasi), skenario 2 (daur ulang, pengomposan dan sanitary landfill) dan skenario 3 (daur ulang, pengomposan, insinerasi dan sanitary landfill). Proses perhitungan dan perkiraan dampak lingkungan oleh masingmasing skenario dilakukan dengan menggunakan software 
SimaPro v.8.3. Perbandingan skenario pengelolaan sampah tersebut menghasilkan satu skenario pengelolaan sampah terbaik yang ditinjau dari aspek lingkungan.

\section{METODE PENELITIAN}

Pada penelitian ini dibutuhkan data primer dan data sekunder. Data primer yang dibutuhkan terdiri data timbulan sampah, komposisi sampah di TPA Jabon, dan karakteristik sampah. Data timbulan sampah yang masuk ke TPA Jabon didapatkan dengan menggunakan metode load count analysis. Komposisi sampah di TPA dilakukan dengan mengacu pada SNI 19-3964-1995 mengenai "Metoda Pengambilan dan Pengukuran Contoh Timbulan Sampah Perkotaan" [7]. Analisis komposisi ini dilakukan secara representatif terhadap kawasan wilayah Kabupaten Sidoarjo. Kabupaten Sidoarjo memiliki 4 kawasan wilayah yakni Sidoarjo barat, timur, utara dan selatan. Sampah di ambil secara spesifik dari truk pengangkut yang membawa sampah dari daerah yang spesifik sebanyak masing-masing 2 kali pemilahan dengan jumlah sampel sekali pemilahan sebanyak $100 \mathrm{~kg}$. Analisis karakteristik sampah dianalisis dengan analisis proximat dan ultimat. Analisis proximat untuk mengetahui kadar air sampah (berat kering), volatile solid sampah, kandungan abu, dan fixed carbon, dan nilai kalor. Analisis ultimat untuk mengetahui kadar $\mathrm{C}, \mathrm{H}, \mathrm{O}$ dan $\mathrm{N}$ di dalam sampah. Data sekunder yang dikumpulkan pada penelitian ini adalah jumlah penduduk Kabupaten Sidoarjo 5 tahun terakhir untuk proyeksi timbulan penduduk dan proyeksi timbulan sampah tahun 2027.

Analisis Life Cycle Assessment (LCA) dilakukan setelah seluruh data telah dikumpulkan. Perkiraan dampak dengan metode LCA menggunakan software SimaPro 8.3 dan metode Environmental Product Declaration (EPD).

\section{HASIL DAN PEMBAHASAN \\ A. Timbulan Sampah Kondisi Eksisting}

Data kuantitas sampah yang masuk ke TPA Jabon diperoleh melalui data primer yang dilakukan dengan melakukan pengamatan terhadap jumlah sampah yang masuk ke TPA Jabon. Hal ini dikarenakan TPA Jabon belum memiliki jembatan timbang, sehingga analisis kuantitas sampah dapat dihitung dari volume sampah yang masuk sesuai jumlah armada pengangkut sampah dan kapasitas masing-masing.

Tabel 1.

Timbulan Sampah TPA Jabon

\begin{tabular}{ccc}
\hline \hline Hari & Timbulan $\left(\mathrm{m}^{3 /}\right.$ hari $)$ & Massa $(\mathrm{kg} /$ hari $)$ \\
\hline 1 & 1218,0 & 332295,4 \\
2 & 1214,4 & 331313,2 \\
3 & 1198,8 & 327057,2 \\
4 & 1193,6 & 325638,5 \\
5 & 1228,0 & 335023,6 \\
6 & 1225,6 & 334368,8 \\
7 & 1201,2 & 327712,0 \\
8 & 1173,6 & 320182,1 \\
\hline Rata-Rata & 1206,65 & 329198,9 \\
\hline \hline
\end{tabular}

Dari data pada Tabel 1, maka didapatkan timbulan sampah yang masuk ke TPA Jabon sebesar 1206,65 $\mathrm{m}^{3} /$ hari atau $329198,9 \mathrm{~kg} / \mathrm{hari}$.
Angka timbulan sampah yang digunakan pada perhitungan adalah sesuai dengan kondisi aktual di lapangan yang dapat dihitung dari jumlah sampah yang masuk dibagi dengan jumlah penduduk yang terlayani tahun 2017 yakni sebesar $0,43 \mathrm{~kg} /$ orang.hari. Proyeksi timbulan sampah yang masuk ke TPA dihitung dengan mengalikan jumlah penduduk dan jumlah timbulan sampah per individu. Proyeksi penduduk untuk Kabupaten Sidoarjo adalah dengan menggunakan metode geometri. Sehingga dapat dilakukan proyeksi timbulan sampah yang masuk ke TPA Jabon mulai dari tahun 2017 hingga tahun 2027 yang terdapat pada Tabel 2.

Tabel 2.

Proyeksi Sampah yang Masuk ke TPA Jabon

\begin{tabular}{ccccc}
\hline \hline Tahun & $\begin{array}{c}\text { Proyeksi } \\
\text { Jumlah } \\
\text { Penduduk } \\
\text { (jiwa/tahun) }\end{array}$ & $\begin{array}{c}\text { Persentase } \\
\text { pelayanan }\end{array}$ & $\begin{array}{c}\text { Proyeksi } \\
\text { Penduduk } \\
\text { Terlayani } \\
\text { (jiwa/tahun) }\end{array}$ & $\begin{array}{c}\text { Jumlah } \\
\text { Sampah } \\
\text { (ton/tahun) }\end{array}$ \\
\hline 2017 & 2035220 & $38 \%$ & 773384 & 120158 \\
2018 & 2038805 & $40 \%$ & 815522 & 126704 \\
2019 & 2042395 & $42 \%$ & 857806 & 133274 \\
2020 & 2045992 & $44 \%$ & 900237 & 139866 \\
2021 & 2049596 & $46 \%$ & 942814 & 146481 \\
2022 & 2053206 & $48 \%$ & 985539 & 153119 \\
2023 & 2056822 & $50 \%$ & 1028411 & 159780 \\
2024 & 2060444 & $52 \%$ & 1071431 & 166464 \\
2025 & 2064073 & $54 \%$ & 1114599 & 173171 \\
2026 & 2067708 & $56 \%$ & 1157917 & 179901 \\
2027 & 2071350 & $58 \%$ & 1201383 & 186654 \\
\hline \hline
\end{tabular}

Kenaikan pelayanan persampahan sebesar $2 \%$ pertahun, hal ini dilihat dari perkembangan pelayanan dari tahun-tahun sebelumnya yang menunjukkan peningkatan rata-rata $2 \%$ per tahun.

B. Komposisi Sampah

Penelitian komposisi sampah pada TPA Jabon dilakukan untuk mengetahui komposisi apa saja yang masuk ke TPA. Hal ini juga menjadi salah satu dasar pertimbangan dalam membuat skenario pengelolaan sampah apakah yang sesuai dengan jumlah komposisi yang ada di TPA Jabon.

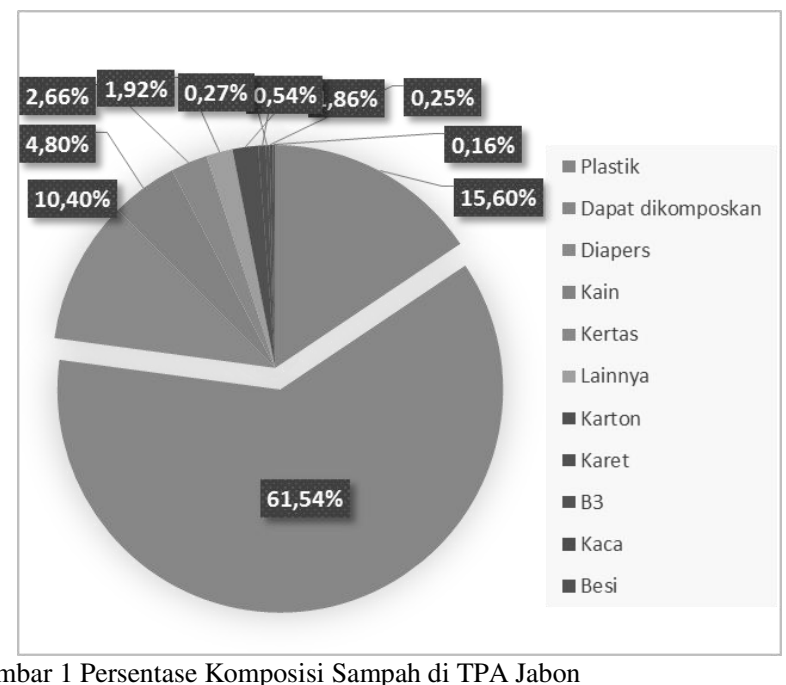

Hasil analisis komposisi sampah tersebut akan mempengaruhi pengelolaan sampah yang tepat untuk dilaksanakan di TPA. Berikut ini adalah penjelasan mengenai komposisi sampah yang dianalisis: 
1. Sampah yang dapat dikomposkan: merupakan sampah yang terdiri dari sampah sisa makanan / kerak dan sampah kebun. Sampah ini memiliki persentase paling tinggi yakni sebesar $34,77 \%$ untuk sampah sisa makanan dan 26,77\% sampah kebun.

2. Plastik: merupakan gabungan dari beberapa jenis plastik yakni HDPE, LDPE, PET, PS Sterofoam, PP bag, dan plastik lainnya. Plastik ini memiliki persentase kedua terbesar yakni sebesar $15,6 \%$.

3. Diapers: terdiri dari popok dan pembalut memiliki persentase sebesar $10,4 \%$.

4. Kain: sampah kain juga memiliki persentase yang cukup besar yakni sebesar $4,8 \%$.

5. Kertas: sampah kertas memiliki persentase sebesar $2,66 \%$.

6. Karton: Sampah karton memiliki persentase sebesar $1,86 \%$.

7. Karet: merupakan sampah seperti sandal bekas, karet gelang, ban bekas. Persentase karet sebesar 0,54\%.

8. Limbah B3: terdiri dari baterai bekas, sisa obat-obatan, lampu bekas, benda terkontaminasi B3, dan lain sebagainya. Persentasenya sebesar $0,27 \%$.

9. Kaca: terdiri dari botol kaca dan pecahan kaca lain. Memiliki persentase sebesar $0,25 \%$.

10. Besi: tediri dari lempengan besi dan kaleng sebesar $0,16 \%$.

11. Lain-lain: Terdiri dari sampah yang yang tidak tergolong dalam spesifikasi kelompok diatas seperti kayu, dll yang bekisar $1,92 \%$.

\section{Analisis Karakteristik Fisik Sampah}

Analisis karakteristik fisik dilakukan di laboratorium dengan analisis proximat. analisis proximat terdiri dari analisis kadar air, volatile solid, fixed carbon, kadar abu. Analisis kadar air bertujuan untuk mengetahui kandungan air dalam sampah. Volatile Solid (Vs) dianalisis untuk mengetahui kandungan bahan organik pada sampah. Analisis abu bertujuan untuk abu yang dihasilkan dari pembakaran sampah.

Analisis karakteristik sampah dibedakan menjadi beberapa jenis yakni sampah organik biowaste (sampah sisa makanan dan sampah kebun), sampah organik non-biswaste (plastik, kertas, karton, kain, karet, dan organik lainnya), bio+nonbiowaste dan sampah tercampur (gabungan sampah organik dan anorganik).

Tabel 3.

Hasil Analisis Proximat

\begin{tabular}{clc}
\hline \hline Parameter & \multicolumn{1}{c}{ Jenis Sampah } & Hasil (\%) \\
\hline \multirow{4}{*}{ Kadar Air } & Organik Biowaste & 74,08 \\
& Organik Non-Biowaste & 35,39 \\
& Organik Bio+Non Biowaste & 54,22 \\
& Tercampur (Organik+Anorganik) & 50,71 \\
\hline \multirow{4}{*}{ Volatile Solid } & Organik Biowaste & 7,05 \\
& Organik Non-Biowaste & 9,12 \\
& Organik Bio+Non Biowaste & 9,54 \\
& Tercampur (Organik+Anorganik) & 9,04 \\
\hline Fixed Karbon & Organik Biowaste & 3,27 \\
\hline
\end{tabular}

\begin{tabular}{clc}
\hline \hline Parameter & \multicolumn{1}{c}{ Jenis Sampah } & Hasil (\%) \\
\hline & Organik Non-Biowaste & 10,26 \\
& Organik Bio+Non Biowaste & 4,93 \\
& Tercampur (Organik+Anorganik) & 2,16 \\
\hline \multirow{5}{*}{ Kadar Abu } & Organik Biowaste & 15,61 \\
& Organik Non-Biowaste & 45,23 \\
& Organik Bio+Non Biowaste & 31,31 \\
& Tercampur (Organik+Anorganik) & 38,10 \\
\hline \hline
\end{tabular}

\section{Analisis Karakteristik Kimia Sampah}

Analisis karakteristik kimia yang dilakukan pada penelitian ini adalah analisis ultimat yang meliputi analisis $\mathrm{C}$, $\mathrm{H}, \mathrm{O}$ dan $\mathrm{N}$.

Tabel 4.

Hasil Analisis Ultimat

\begin{tabular}{clcc}
\hline \hline No & \multicolumn{1}{c}{ Nama Sampel } & Parameter & $\begin{array}{c}\text { Nilai } \\
(\%)\end{array}$ \\
\hline \multirow{4}{*}{1} & Organik Biowaste & & 0,59 \\
& Organik Bio+Non Biowaste & Total N & 1,93 \\
& Tercampur (Organik+Anorganik) & & 1,22 \\
& Organik Non Biowaste & & 1,50 \\
\hline \multirow{4}{*}{2 Organik Biowaste } & Hidrogen & 5,51 \\
& Organik Bio+Non Biowaste & 5,88 \\
& Tercampur (Organik+Anorganik) & & 5,58 \\
& Organik Non Biowaste & & 54,25 \\
\hline \multirow{4}{*}{3 Organik Biowaste } & Karbon & 49,01 \\
& Organik Bio+Non Biowaste & 46,53 \\
& Tercampur (Organik+Anorganik) & & 49,86 \\
\hline \multirow{4}{*}{4 Organik Non Biowaste } & Organik Biowaste & 38,65 \\
Organik Bio+Non Biowaste & & 43,18 \\
& Tercampur (Organik+Anorganik) & Oksigen & 46,67 \\
& Organik Non Biowaste & & 42,65 \\
\hline \hline
\end{tabular}

Komposisi unsur kimia untuk masing-masing jenis sampah adalah:
a. Sampah organik biowaste $=\mathrm{C}_{107} \mathrm{H}_{153} \mathrm{O}_{57} \mathrm{~N}$
b. Sampah organik bio+nonbiowaste $=\mathrm{C}_{30} \mathrm{H}_{42} \mathrm{O}_{20} \mathrm{~N}$
c. Sampah organik non-biowaste $=\mathrm{C}_{39} \mathrm{H}_{55} \mathrm{O}_{25} \mathrm{~N}$
d. Sampah tercampur (organik dan anorganik) = $\mathrm{C}_{45} \mathrm{H}_{64} \mathrm{O}_{34} \mathrm{~N}$

\section{E. Analisis Life Cycle Assessment (LCA)}

Life Cycle Assessment (LCA) lingkungan adalah sebuah metode untuk melakukan analisis. LCA menganalisis aspek lingkungan dan dampak yang berpotesi terhadap keseluruhan siklus suatu "produk" dari bahan mentah hingga produksi, penggunaan hingga pembuangan akhir. Arti LCA dalam kalimat "produk" dalam konteksi ini adalah sistem pelayanan, yakni sistem pengelolaan sampah [8]

1. Penentuan Tujuan dan Batasan

Tujuan (goal) dari penggunaaan metode LCA adalah untuk mengetahui dampak lingkungan (terdiri dari gas rumah kaca, asidifikasi, eutrofikasi, photochemical oxidation, ozone layer depletion, dan abiotic depletion) yang dihasikan dari masing-masing skenario pengelolaan sampah yang direncanakan. Dalam batasan penelitian ini, fungsi unit yang digunakan untuk Life Cycle Inventory (LCI) adalah kuantitas sampah pada tahun 2017 dan tahun proyeksi yakni tahun 2027. Kuantitas sampah yang 
digunakan adalah kuantitas sampah yang masuk ke TPA Jabon Kabupaten Sidoarjo.

2. Inventarisasi Data

Life Cycle Inventory (LCI) merupakan proses inventarisasi data berupa bahan dan energi yang digunakan pada saat proses masing-masing skenario. LCI dianalisis untuk tahun 2017 dan tahun proyeksi (tahun 2027). LCI didapatkan dengan mengalikan persentase sampah dengan kuantitas sampah eksisting 2017 dan sampah pada tahun 2027.

\begin{tabular}{|c|c|c|c|}
\hline \multirow{2}{*}{ Jenis Sampah } & \multirow{2}{*}{$\begin{array}{l}\text { Prosentase } \\
\text { masing- } \\
\text { masing } \\
\text { sampah }(\%)\end{array}$} & \multicolumn{2}{|c|}{$\begin{array}{l}\text { Kuantitas sampah tiap } \\
\text { komposisi (ton) }\end{array}$} \\
\hline & & 2017 & 2027 \\
\hline \multicolumn{4}{|l|}{ Plastik } \\
\hline HDPE & $1,95 \%$ & 2341,57 & 3637,42 \\
\hline LDPE & $10,95 \%$ & 13152,75 & 20431,63 \\
\hline \multicolumn{4}{|l|}{ PET } \\
\hline -warna & $0,23 \%$ & 280,87 & 436,30 \\
\hline -transparan & $0,50 \%$ & 599,29 & 930,94 \\
\hline PS sterofoam & $0,29 \%$ & 352,96 & 548,30 \\
\hline PP bag & $0,37 \%$ & 443,08 & 688,29 \\
\hline others & $1,31 \%$ & 1575,57 & 2447,50 \\
\hline Sub Total Plastik & $15,60 \%$ & 18746,08 & 29120,38 \\
\hline \multicolumn{4}{|l|}{ Dapat dikomposkan } \\
\hline sisa makanan/karak & $34,77 \%$ & 41777,29 & 64897,31 \\
\hline sampah kebun/taman & $26,77 \%$ & 32164,68 & 49964,98 \\
\hline $\begin{array}{l}\text { Sub Total Dapat } \\
\text { dikomposkan }\end{array}$ & $61,54 \%$ & 73941,97 & 114862,30 \\
\hline \multicolumn{4}{|l|}{ Kertas } \\
\hline Majalah & $0,44 \%$ & 531,70 & 825,94 \\
\hline Buku & $0,90 \%$ & 1076,91 & 1672,89 \\
\hline koran & $0,43 \%$ & 515,18 & 800,28 \\
\hline HVS/duplek & $0,45 \%$ & 537,71 & 835,28 \\
\hline others & $1,78 \%$ & 2140,31 & 3324,78 \\
\hline Sub Total Kertas & $2,66 \%$ & 4801,80 & 7459,17 \\
\hline Karton & $1,86 \%$ & 2237,93 & 3476,43 \\
\hline \multicolumn{4}{|l|}{ Besi } \\
\hline -kaleng & $0,05 \%$ & 54,07 & 83,99 \\
\hline -non kaleng & $0,06 \%$ & 67,59 & 104,99 \\
\hline non besi & $0,02 \%$ & 28,54 & 44,33 \\
\hline Kabel (tembaga) & $0,04 \%$ & 45,06 & 70,00 \\
\hline Sub Total Besi & $0,16 \%$ & 195,26 & 303,31 \\
\hline \multicolumn{4}{|l|}{ Kaca } \\
\hline botol kaca & $0,09 \%$ & 108,14 & 167,99 \\
\hline kaca lain & $0,17 \%$ & 207,27 & 321,98 \\
\hline Sub Total Kaca & $0,25 \%$ & 315,41 & 489,97 \\
\hline
\end{tabular}

\begin{tabular}{lccc} 
Kain & $4,80 \%$ & 5770,57 & 8964,07 \\
Karet & $0,54 \%$ & 648,85 & 1007,93 \\
Diapers & & & \\
popok & $9,58 \%$ & 11508,09 & 17876,80 \\
non popok (pembalut) & $0,82 \%$ & 989,80 & 1537,56 \\
Sub Total Diapers & $10,40 \%$ & 12497,89 & 19414,36 \\
Lainnya & $1,92 \%$ & 2311,53 & 3590,76 \\
B3 & $0,27 \%$ & 319,92 & 496,97 \\
\hline Total & $100 \%$ & 120157,58 & 186654,15 \\
\hline \hline
\end{tabular}

Nilai input data pada tabel 5 , selanjutnya akan digunakan untuk dimasukkan ke dalam software SimaPro v.8.3.

3. Perkiraan Dampak Pada LCA

Perkiraan dampak pada penelitian ini menggunakan software SimaPro v.8.3. Metode pada SimaPro yang digunakan untuk memperkirakan besarnya dampak yang terjadi pada penelitian ini adalah metode EPD (2013). Hasil yang didapatkan adalah dampak per unit fungsi. Skenario pengelolaan sampah yang dikaji dalam penelitian ini adalah skenario 0 (controlled landfill), skenario 1 (pengomposan, daur ulang, insinerasi), skenario 2 (pengomposan, daur ulang, sanitary landfill), dan skenario 3 (pengomposan, daur ulang, insinerasi, dan sanitary landfill).

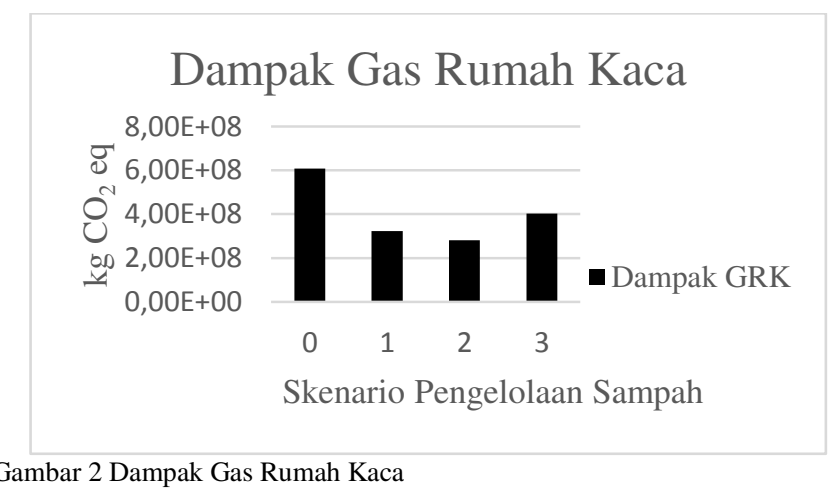

Gambar 2 Dampak Gas Rumah Kaca

Dampak Gas Rumah Kaca (GRK) skenario 0 adalah 6,09E8 $\mathrm{kg} \mathrm{CO} 2$ eq, skenario 1 adalah 3,23E8 $\mathrm{kg} \mathrm{CO} 2 \mathrm{eq}$, skenario 2 adalah 2,82E8 $\mathrm{kg} \mathrm{CO} 2 \mathrm{eq}$, dan skenario 3 adalah $4,03 \mathrm{E} 8 \mathrm{~kg} \mathrm{CO} 2$ eq.

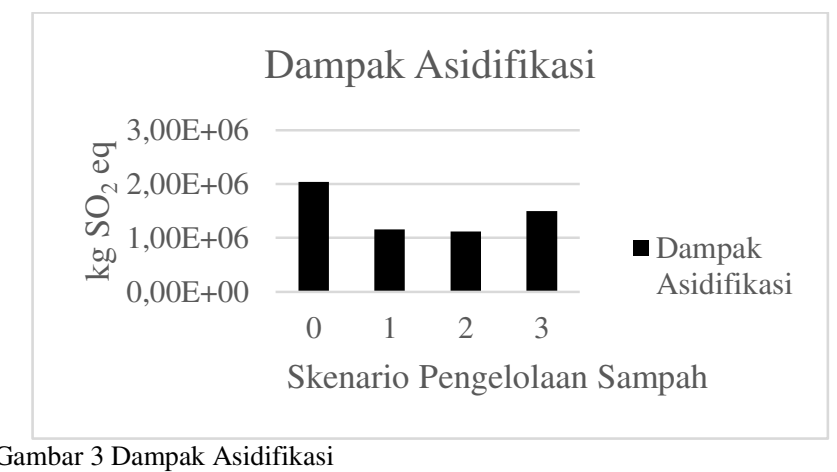

Gambar 3 Dampak Asidifikasi 
Dampak asidifikasi untuk skenario 0 adalah sebesar 2,04E6 $\mathrm{kg} \mathrm{SO}_{2}$ eq, skenario 1 adalah $1,15 \mathrm{E} 6 \mathrm{~kg} \mathrm{SO}_{2}$ eq, skenario 2 adalah 1,12E6 $\mathrm{kg} \mathrm{SO}_{2}$ eq, dan skenario 3 adalah 1,5E6 $\mathrm{kg} \mathrm{SO}_{2}$ eq.

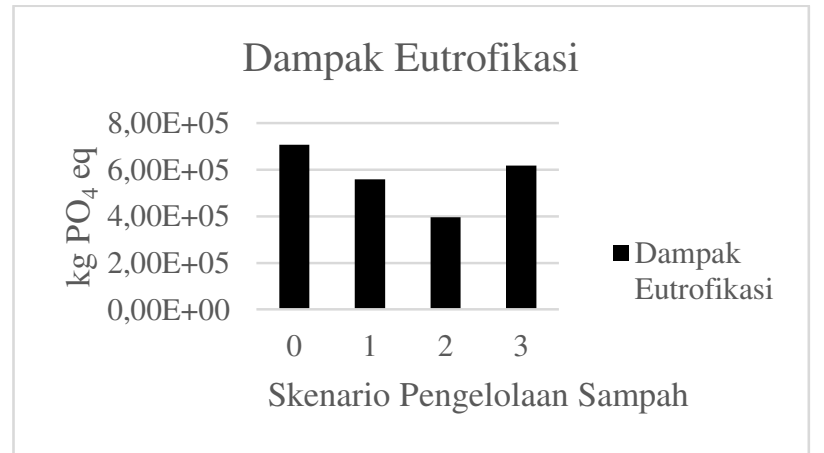

Gambar 4. Dampak Eutrofikasi

Dampak eutrofikasi untuk skenario 0 adalah 7,07E5 kg $\mathrm{PO}_{4}$ eq, skenario 1 adalah 5,58E5 $\mathrm{kg} \mathrm{PO}_{4}$ eq, skenario 2 adalah $3,95 \mathrm{E} 5 \mathrm{~kg} \mathrm{PO}_{4}$ eq, dan skenario 3 adalah 6,17E5 $\mathrm{kg} \mathrm{PO}_{4}$ eq.

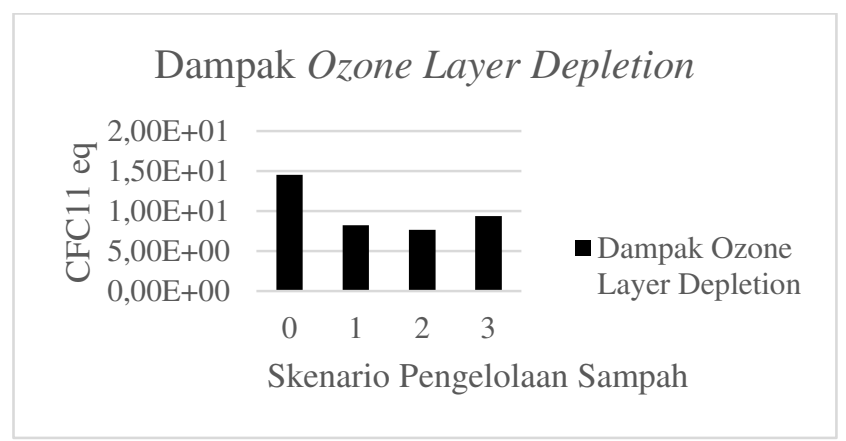

Gambar 5. Dampak Ozone Layer Depletion

Dampak ozone layer depletion untuk skenario 0 adalah 14,5 kg CFC-11 eq, skenario 1 adalah 8,23 kg CFC-11 eq, skenario 2 adalah 7,68 kg CFC-11 eq, dan skenario 3 adalah 9,39 kg CFC-11 eq.

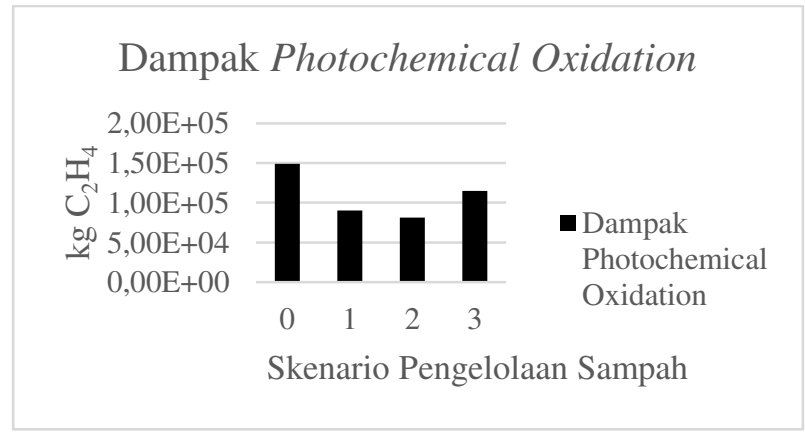

Gambar 6 Dampak Photocemical Oxidation

Dampak photocemical oxidation untuk skenario 0 adalah 5,54E4 $\mathrm{kg} \mathrm{C}_{2} \mathrm{H}_{4}$ eq, skenario 1 adalah 9,01E4 $\mathrm{kg} \mathrm{C}_{2} \mathrm{H}_{4}$ eq, skenario 2 adalah 8,12E4 $\mathrm{kg} \mathrm{C}_{2} \mathrm{H}_{4}$ eq, dan skenario 3 adalah $1,15 \mathrm{E} 5 \mathrm{~kg} \mathrm{C}_{2} \mathrm{H}_{4}$ eq.

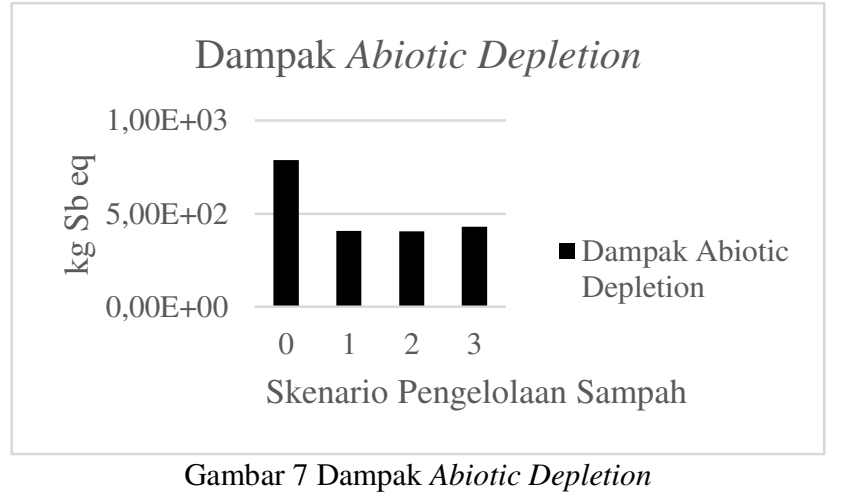

Dampak abiotic depletion untuk skenario 0 adalah $787 \mathrm{~kg} \mathrm{Sb}$ eq, skenario 1 adalah $408 \mathrm{~kg} \mathrm{Sb}$ eq, skenario 2 adalah $405 \mathrm{~kg}$ $\mathrm{Sb}$ eq, dan skenario 3 adalah $429 \mathrm{~kg} \mathrm{Sb}$ eq.

4. Interpretasi

Interpretasi adalah tahap terakhir dari analisis LCA, yakni penarikan kesimpulan dari potensi pencemaran lingkungan oleh skenario pengelolaan sampah di TPA Jabon. Dari hasil potensi pencemaran yang dihasilkan dari analisis LCA dengan software SimaPro, nilai dampak terkecil yang dihasilkan adalah pada skenario 2, yakni daur ulang, pengomposan, dan sanitary landfill. Skenario 2 merupakan skenario paling tepat untuk TPA Jabon adalah karena dari komposisi sampah TPA yang sebagian besar merupakan sampah yang dapat dikomposkan, maka pengomposan dinilai tepat untuk pengolahan sampah biodegradable. Daur ulang merupakan pengolahan yang baik karena mampu memanfaatkan sampah menjadi produk yang dapat digunakan, juga untuk sistem penimbunan sanitary landfill dinilai lebih baik dibandingkan pengolahan termal insinerasi dikarenakan proses pembakaran termal lebih bayak menggunakan energi

\section{KESIMPULAN}

Berdasarkan penelitian yang telah dilakukan, maka dapat diambil kesimpulan bahwa skenario pengelolaan sampah terbaik untuk TPA Jabon adalah skenario 2 (daur ulang, pengomposan, dan sanitary landfill).

\section{UCAPAN TERIMA KASIH}

Penulis mengucapkan terimakasih kepada Dinas Lingkungan Hidup dan Kebersihan (DLHK) dan UPT Griyomulyo Kabupaten Sidoarjo atas bantuan kepada penulis selama proses analisis di lapangan.

\section{DAFTAR PUSTAKA}

[1] R.O. Zakharia, M. Makmur dan M. Rozikin. 2014. Implementasi Program Sidoarjo Bersih dan Hijau yang Tertuang dalam Surat Keputusan Bupati No 188 tentang Tim Sidoarjo Bersih dan Hijau. Jurnal Administrasi Publik (JAP), Vol. 2, No. 4, Hal. 666-672. 
[2] S. Saheri, M. A. Mir., Noor E.A.B., N. Z.Basri, N. Z. B. Mahmood dan Rawshan A.B. 2012. Life Cycle Assessment for Solid Waste Disposal Option in Malaysia. Pol. J. Environ, Stud. Vol. 21, No. 5 (2012), 13771382.

[3] Dinas Lingkungan Hidup dan Kebersihan Kabupaten Sidoarjo. 2017.

[4] Sunarto, S. P. Hadi dan Purwanto. 2013. Pengolahan Sampah Di TPS Tlogomas Malang untuk Mereduksi Jejak Karbon. Prosiding Seminar Nasional Pengelolaan Sumberdaya Alam dan Lingkungan 2013.

[5] P. Yadav dan S.R Samandder. 2014. Life cycle assessment of solid waste management options: A Review. Recent research in Science and Technology 2014, 6(1): 113-116.
[6] A.H Palupi., I. P.Tama, dan R. A. Sari. 2014. Evaluasi Dampak Lingkungan Produk Kertas dengan Menggunakan Life Cycle Assessment (LCA) dan Analitic Network Process (ANP). Jurnal Rekayasa dan Manajemen Sistem Industri Vol.2 No. 5 Halaman 2.

[7] Badan Standarisasi Nasional (BSN). 1995. SNI 19-3964-1995 tentang Metoda Pengambilan dan Pengukuran Contoh Timbulan Sampah Perkotaan. Jakarta.

[8] M. Banar., Z. Cokaygil, dan A. Ozka. 2009. Life Cycle Assessment of Solid Waste Management Options for Eskisehir, Turkey. Waste Management 29 (2009) 54-62. 